\title{
Technology Sharing and Competitiveness in a Stackelberg Model
}

\author{
- Junlong Chen, Zihan Wei, Jiali Liu, Xiaosong Zheng
}

\begin{abstract}
The existing literature has made great achievements in technology sharing (licensing patents) contracts, which has defects in the selection of oligopoly models, the setting of innovation subjects, the consideration of product heterogeneity, and production costs. This paper aims to reveal the competitiveness strategies of leaders and followers for innovation, technology sharing, and sharing fees in a Stackelberg market. The three-stage sequential game method is used to achieve the objective. The results are as follows. First, whether an enterprise uses innovation or shares technology is related to the fixed cost of innovation, the return on innovation, and product differentiation. It will hinder innovation activities if the fixed cost of innovation is too high, the return on innovation is too low, or the products are too homogeneous. A relatively low return on innovation makes it possible for the two enterprises to engage in sharing. However, with a relatively high return on innovation, only a high level of product differentiation can ensure technology sharing. Second, the optimal sharing fee is dynamic, showing an upward and then downward trend as the return on innovation grows. Product differentiation has an uncertain impact on the cost. Third, either the leader or the follower is likely to be the optimal bearer of social responsibility depending on the returns on innovation and product differentiation. This study has theoretical significance for optimizing technology-sharing decisions, improving competitiveness for enterprises, and formulating effective industrial policy for the government. And it provides some practical guidance for competition and cooperation between enterprises with technological innovation behavior.
\end{abstract}

Keywords: competitiveness, technology sharing, Stackelberg competition, sharing fee, product differentiation JEL Classification: L11, L13, M2

Received: February, 2021

1st Revision: July, 2021

Accepted: July, 2021

\section{INTRODUCTION}

Technology is essential for enterprises to maintain long-term competitiveness. Technological innovation has significant impacts on enterprises and their competitors, which can enhance product competitiveness for an enterprise and improve its profits. In the process of technological innovation, some enterprises will share technology through patent licensing, technology transfer, and other options, which has become common market behavior (Nguyen et al., 2017; Wang et al., 2018). Innovative enterprises can make up for R\&D costs and create shared benefits through the shared technology. Although enterprises that accept technology have to pay a fee, they also obtain 
advanced technology. What are the impacts of technology sharing on the competitiveness of both supply and demand? What are the conditions under which the enterprises share technology? What is the optimal fee for technology sharing fee? These issues are significant for enterprises' decisions to share technology aimed at improving competitiveness. Hence, the main aims of this paper are as follows. First, this paper seeks to determine the conditions under which technology sharing is implemented. Second, the paper intends to determine the optimal technology sharing fee and the factors affecting the sharing fee and total profits, consumer surplus, and social welfare.

Technology sharing describes a transfer of technology between two or more enterprises. The enterprise that owns the technology shares the technology with other enterprises at a specific cost, which can spread technology and improve the efficiency of resource allocation. There are many forms of technology sharing, among which patent licensing is the primary method. Much research focuses on licensing patents, which provides useful information for this study. Regarding whether an enterprise licenses patents, it has been found that the equilibrium point between the revenue effect and the rent dissipation effect is related to the impacts of diverse factors, including industry characteristics, the intensity of market competition, enterprise size, the intellectual property system, technology transaction costs, and others (Jeon \& Lefouili, 2018; Moreira et al., 2019; Niu, 2019; Yang et al., 2019). With the continuous advancement of research on patent licensing fees, some scholars use a mixed oligopoly model to explore the optimal model for licensing patents (Kitagawa et al., 2020; Sen \& Tauman, 2018; Wang et al., 2020; Din \& Sun, 2020).

This paper has two main contributions that fill gaps in the existing scientific literature. First, the majority of the existing literature adopts simultaneous games such as Cournot and Bertrand competitions (Colombo \& Filippini, 2015; San Martin \& Saracho, 2016; Kishimoto, 2020). Some literature also considers the priorities for decision-making between enterprises and determines the optimal licensing contract in a Stackelberg model (Ferreira \& Bode, 2013; Zhang et al., 2016), but these studies only consider the situation where the leader holds a new technology. This paper introduces a Stackelberg model to analyze a technology-sharing game in which either the leader or the follower is the innovator, which is beneficial to promoting game theory research in technology sharing. Second, there are some limitations in existing studies regarding product differentiation and production cost. Some theoretical studies assume that products between enterprises are homogeneous (Cao \& Kabiraj, 2018; Colombo \& Filippini, 2015).

Furthermore, the assumption of a constant marginal cost commonly neglects the impact of innovation on enterprises' cost reduction (San Martin \& Saracho, 2015), which is not realistic. To solve these problems, we introduce product differentiation into our model, assume that the marginal cost is incremental, and consider the role of innovation in cost savings. Then, we examine the impacts of product differentiation and returns on innovation and technology sharing, and equilibrium results.

The applicability and practicality of this study are as follows (see Table1). First, innovation and technology can be linked to specific development goals of enterprises, and a good technologysharing contract expands the boundaries of technology use and benefits. Specifically, on the one hand, technological innovation often implies creating new production methods and processes. By considering technology sharing, this paper can provide feasible efficiency improvement and cost reduction solutions for enterprises with a high-end technology R\&D behavior; on the other hand, adapted to sustainable development goals, technology sharing can help reduce externalities 
to stimulate resource-consuming enterprises to use new technologies and develop a circular economy to achieve ecosystem services, and balance economic development and natural resource conservation (Kapsalis et al., 2019; Aravossis et al., 2019; Kyriakopoulos et al., 2019). Second, due to enterprises' pursuit of economies of scale, control over production resources and proprietary technologies, and government support, oligopolistic market structures can be widely found in many industries and are characterized by intense competition and high efficiency. Also, Stackelberg is a common type of oligopolistic market structure in the real market competition. Therefore, for enterprises in different market positions, this study provides perspectives for reaching technologysharing contracts. In particular, it has practical implications for small enterprises in the follower position to promote their technology development and enhance their competitiveness through cooperation. This will help improve the overall technology of the industry, which is a reference value for the competition and cooperation between enterprises with technological innovation behavior within industrial organizations.

Tab. 1 - The applicability and practicality of this study. Source: own research

\begin{tabular}{|l|l|}
\hline The value of the study & Applicable fields \\
\hline $\begin{array}{l}\text { Technology sharing: providing efficiency and } \\
\text { cost reduction solutions }\end{array}$ & $\begin{array}{l}\text { Enterprises with high-end technology } \\
\text { research and development behavior }\end{array}$ \\
\hline $\begin{array}{l}\text { An exploration to sharing fee: providing } \\
\text { a framework for inter-organizational } \\
\text { cooperation among resource-consuming } \\
\text { enterprises }\end{array}$ & $\begin{array}{l}\text { Industries that require energy-saving } \\
\text { technologies and circular economy processes } \\
\text { for the treatment of organic waste, garbage, } \\
\text { and sewage, such as the food industry and } \\
\text { the petrochemical industry }\end{array}$ \\
\hline $\begin{array}{l}\text { To help the technology cooperation between } \\
\text { large and small enterprises in the industry }\end{array}$ & $\begin{array}{l}\text { Oligopolistic markets, such as the iron and } \\
\text { steel industry, the cement industry }\end{array}$ \\
\hline
\end{tabular}

\section{THEORETICAL BACKGROUND}

Technology sharing is an effective way to improve the technological capacity of enterprises and promote economic growth. R\&D (Research and Development) can enhance the technological level and market competitiveness of the enterprise, but it is costly and uncertain. Technology sharing can help innovative enterprises reduce costs and help noninnovative enterprises acquire new technologies at a lower cost (Ferreira \& Bode, 2020). The existing literature focuses on forming optimal sharing contracts, and licensing patents is the most common form of a sharing contract. In summary, the current literature is very rich, which provides an excellent theoretical foundation for this paper. Based on existing research, this paper intends to advance the literature.

For technology sharing (licensing patents) contracts, many scholars assume an inside innovator in the market and use a mixed oligopoly model (e.g., the Cournot model and the Bertrand model) to explore the factors that affect the contract. Many factors are considered, such as the initial cost advantage or efficiency difference, the cost function, state-owned shares, the industry size, and the cost of innovation. Li \& Ji (2010) find that competition is not fierce when the degree of product differentiation is high under both the Cournot model and the Bertrand model. Poddar 
\& Sinha (2010) indicate the same point as well. By extending the model by Poddar \& Sinha (2010), Wang et al. (2013) focus on the effect of efficiency differences among enterprises on the choice of the optimal licensing contract and investigate whether the optimal licensing contract is exclusive or nonexclusive based on the relative cost advantage between the two licensees. Colombo \& Filippini (2015) show that in the case of non-drastic innovation, if the cost function is barely convex or highly convex, medium-low convex, or medium-high convex, the patentee would maximize profits by making an ad valorem fee, a fixed fee, or a two-part per-unit royalty, respectively. In the case of drastic innovation, the patentee always provides an ad valorem fee contract. San Martin \& Saracho (2015) deem that in the Cournot duopoly model considering product differentiation, the optimal contract consisting of fixed and ad valorem fees depends on product differentiation, the availability of substitutes, and the intensity of innovation. San Martin \& Saracho (2016) show that the inside patentee prefers ad valorem royalties to fixed fees under the Cournot duopoly model. Gelves \& Heywood (2016) note that a cost-disadvantaged innovator increasingly relies on licensing with a fixed fee as its state-owned shares grow. Kabiraj \& Kabiraj (2017) show that a tariff on foreign products can influence the licensing strategy of the foreign firm in an international Cournot model. Cheng et al. (2018) investigate that the probability of cooperation between the two enterprises increases when fixed fees and cost savings from licensing technology increase simultaneously and find that a modest royalty fee promotes successful cooperation. Moreira et al. (2019) show that enterprises with higher product market competition and exogenous sunk costs are more reluctant to license their technologies. In contrast, a high level of openness to external knowledge increases enterprises' willingness to grant access to internally developed technologies. Yang et al. (2019) show that the sourcing models of the downstream manufacturer and the risk level of the rival should be considered when the incumbent decides whether to license to its rival and what kind of licensing contract to use. Badia (2019) analyzes patent licensing and technological catch-up in a heterogeneous duopoly. Tsai et al. (2019) show that the patentee's optimum strategy is affected by market scale, the incidence of market scale, and the magnitude of cost savings. Zou \& Chen (2020) examine product innovation licensing in a vertically differentiated Cournot oligopoly and show that optimal licensing depends on product differences and patent exclusivity. Kitagawa et al. (2020) conclude that the optimal licensing contract relies on the cost of innovation, market size, and substitution coefficient. Cao \& Sinha (2020) find that the degree of inter-brand differentiation affects the optimal intra-brand patent licensing contract under inter-brand competition. In summary, these studies are rich and provide essential theoretical background for this research.

In the existing research, there are three types of technology sharing (patent licensing), which are the fixed fee (independent of the unit of output), the ad valorem royalty, or the per-unit royalty (a certain fee based on the unit of product or the price of product) and the two-part patent licensing fee, and there is a debate about which is optimal. For example, Wang et al. (2013) and Fan et al. (2018) deem that private enterprises will use fixed fees when there is a considerable initial cost disadvantage, and two-part fees will be adopted when there is an intermediate initial cost disadvantage for themselves and a slight initial cost disadvantage for their competitors. Yan \& Yang (2018) investigate the optimal licensing contract in a differentiated Bertrand duopoly market with non-drastic innovation and show that the optimal licensing contract is fixed-fee licensing when product substitution and technology spillover are both small. Xu \& Tan (2019) 
deem that fixed-fee licensing is superior to royalty licensing considering both regions. Sen \& Tauman (2018) believe that royalties are superior to fixed fees for the innovator. In contrast, fixed-fee policies result in higher consumer surplus and welfare than royalty and FR policies when the industry size is relatively large. Zhang et al. (2018) find that royalty licensing is optimal when the network effect is low. Hsu et al. (2019) find that ad valorem royalty licensing is superior to per-unit royalty licensing for the supplier if cost-reducing innovation is non-drastic. From the above literature, it is suitable to use a royalty contract for our model. This paper assumes that the innovative enterprise uses a per-unit royalty and determines the optimal sharing fee.

Some studies set up a Stackelberg model to examine the optimal licensing contract and investigate the influence of several factors, including product differentiation, cost advantage, and technology spillover, on the type of patent licensing contract. Li \& Yanagawa (2011) find that if products are fairly differentiated and the cost advantages are significant, the leader will use a fixed contract. However, if the cost advantages are small or the products are very similar, the leader will use a royalty contract. Ferreira \& Bode (2013) consider the effects of product heterogeneity on the size of innovation, the optimal fee, consumer surplus, and social welfare with different types of contracts in a Stackelberg model. Hong et al. (2014) show that with nondrastic innovation, royalty licensing is always better than fixed-fee licensing for the innovator. Zhang et al. (2016) conclude that whether the innovator (the leader) chooses fixed-fee licensing or royalty licensing depends on the degree of product differentiation and technology spillover. The studies above assume that only the leader can be an innovator. By considering the possibility for the leader or the follower to be the innovator, Cao \& Kabiraj (2018) compare the impact of different patent licensing contracts on social welfare with varying sizes of innovation and patent owners (leader or follower) and show that when the innovation is non-drastic, a royalty contract dominates the fee contract for the patent holder. In reality, technology sharing does exist in a Stackelberg competition. Therefore, this paper also constructs a Stackelberg model to analyze the technology sharing and competitiveness between two enterprises.

\section{OBJECTIVE AND METHODOLOGY}

Our objectives are as follows. First, we derive the equilibrium results of technology sharing when the leader or the follower acts as the innovator. Second, based on the equilibrium results, we analyze the conditions and optimal sharing fees for the two enterprises to reach technology sharing and explore the trends of sharing fees influenced by returns on innovation and product differentiation. Third, we explore the conditions for enterprises to engage in technological innovation. Finally, we compare the equilibrium outcomes under different innovators (leader or follower) and reveal the impacts of various innovators under different returns on innovation and product differentiation.

To achieve the objectives, this paper adopts a sequential game method to set up an oligopoly model that can provide a desirable tool for cooperation and competition between multiple subjects in different scenarios. The sequential game method and the oligopoly model have been widely used in academia and are widely recognized (Amemiya et al., 2020; Chen et al., 2019). The oligopoly market is a market structure between perfect competition and perfect monopoly. The oligopoly 
model has a strong theoretical foundation and has strong applicability and expandability. The assumption of the Stackelberg model is a classical assumption in the study of oligopoly models, and this form can be considered a generalizing constraint against real-world conditions. The sequential game method is a typical method applied to the analysis of oligopoly models. In this paper, the sequential game is employed to explore the equilibrium outcomes of technology sharing and competition between two competing enterprises. We construct an oligopoly model of technology sharing between two enterprises under Stackelberg's competition.

1. There exists a Stackelberg duopoly market consisting of Enterprise 1 (the leader) and Enterprise 2 (the follower). $r \in[0,1]$ reflects the product differentiation between the two enterprises, and there is no difference between the two enterprises when $r=1$. Following Chen et al. (2020a, 2020b), the market demand function can be expressed as

$p_{i}=a-q_{i}-r q_{j}(i, j=1,2$ and $i \neq j)$

2. Both enterprises pursue profit maximization. We specify the cost function as $C_{i}=1 / 2\left(q_{i}\right)^{2}$, where $i=1,2$, indicating that the marginal cost is incremental. Suppose the social welfare is $s w=\pi_{1}+\pi_{2}+c s$ where consumer surplus $c s=\left(q_{1}{ }^{2}+q_{2}{ }^{2}+2 r q_{1} q_{2}\right) / 2$.

3. Suppose that one enterprise innovates. By paying a fixed cost $F$, the innovating enterprise can reduce the cost by e per unit, which means that the returns on innovation are e per unit. The fixed cost of innovation $\mathrm{F}$ is a sunk cost in the first stage. We assume that $C_{i}=1 / 2\left(q_{i}\right)^{2} \geq e q_{i}$, $i=1,2$, so there will not be a situation where the total production cost is negative for small $q_{i}$. The innovating enterprise can choose to share the technology with the non-innovating enterprise by charging a sharing fee, $f$, per unit. Enterprise 1 or 2 can engage in innovation and can accept or reject technology sharing. The situation where neither enterprise innovates is denoted as NN. A situation denoted as $R N$ indicates that one enterprise innovates without technology sharing. In contrast, when the two enterprises share technology, it is denoted as RS. The technology sharing models with Enterprise 1 or Enterprise 2 as innovators are denoted as Model L and Model F, respectively. When firm $j$ observes the same results for accepting or rejecting technology sharing, firm $j$ will choose to accept technology sharing.

4. We set up a three-stage sequential game between the two enterprises. In the first stage, the innovation-decision of Enterprise $i$ depends on whether

$\pi_{i}^{R N}=\left(p_{i}^{R N-1 / 2} q_{i}^{R N+e)} q_{i}^{R N}-F \geq \pi_{i}^{N N}\right.$

is satisfied, where the profit of Enterprise $i$ without innovation is described as

$\pi_{i}^{N N}=\left(p_{i}^{N N}-1 / 2 q_{i}^{N N}\right) q_{i}^{N N}$

In the second stage, Enterprise $i$ decides whether to share technology according to profit maximization and how to charge a sharing fee per unit of product $f$. Enterprise $j$ decides whether to accept sharing and, if so, pays a sharing fee $f$. The cooperation with shared technology is dependent on the following conditions:

$\pi_{i}^{R S}=\left(p_{i}^{R S-1 / 2} q_{i}^{R S}+e\right) q_{i}^{R S}+f q_{j}^{R S}-F \geq \pi_{i}^{R N}$

$\pi_{j}^{R S}=\left(p_{j}^{R S-1 / 2} q_{j}^{R S+e-f)} q_{j}^{R S \geq \pi_{j}^{R N}}\right.$

In the third stage, the enterprises determine their optimal outputs under Stackelberg competition. 
5. Based on the results of the three-stage sequential game, we compare the total profits, consumer surplus, and social welfare under different innovators (leader or follower) and explore the impacts of different innovators on the total profits, consumer surplus, and social welfare under different returns on innovation and product differentiation. The comparative results can distinguish the effects of different technological innovation subjects and guide enterprises to optimize decision-making and government regulation policies on technology sharing to achieve win-win cooperation.

\section{RESULTS}

\subsection{Results of Model L}

In the third stage of the game, Enterprise 1 shares technology with Enterprise 2 and charges a fee $f$ per unit of product, and we can obtain the equilibrium results of Model L.

In Stage 2, it must be profitable for both Enterprise 1 and Enterprise 2, which satisfies

$\pi_{1}^{R S}-\pi_{1}^{R N} \geq 0$

$\pi_{2}^{R S}-\pi_{2}^{R N} \geq 0$

Result 1-1: The optimal sharing fee of Model L is:

(1) If $e \leq \frac{a\left(-r^{2}-3 r+9\right)}{3\left(-4 r^{2}+r+18\right)}$, then $f^{*}=\frac{e\left(9-r^{2}\right)}{9-2 r^{2}}$.

(2) If $\frac{a\left(-r^{2}-3 r+9\right)}{3\left(-4 r^{2}+r+18\right)}<e \leq e(r)$, then $f^{*}=\frac{\left(-r^{2}-3 r+9\right) a-\left(-11 r^{2}+3 r+45\right) e}{9-2 r^{2}}$, where $e(r)=$ $\frac{78 a\left(-r^{2}+\frac{3}{13} r+\frac{54}{13}\right)\left(\frac{3}{2}-r\right)+24 a \sqrt{\left(\frac{9}{2}-r^{2}\right)\left(-r^{6}+\frac{13}{24} r^{5}+\frac{355}{32} r^{4}-\frac{1611}{32} r^{2}-\frac{81}{8} r+\frac{729}{8}\right)}}{288 r^{4}-156 r^{3}-2349 r^{2}+648 r+4860}$ and $\frac{\partial e(r)}{\partial r}<0$.

(3) If $e>e(r)$, then there is no shared technology.

As shown in Result 1-1, when Enterprise 1 (the leader) engages in innovative activities, only if $e \leq e(r)$ can the two enterprises cooperate and share technology. Otherwise, Enterprise 1 would not profit. The reason for this finding is that excessive returns on innovation can increase the competitiveness of the competitor, thus affecting the innovator's profit. In addition, the returns on innovation can affect the choice of strategies to share technology among enterprises producing differentiated products. When the return on innovation e is high enough, $r \in\left[0, r_{0}\right]$ must be satisfied according to $e \leq e(r)$, which means enterprises with higher product differentiation are more likely to cooperate. When the two enterprises have a high level of product homogeneity, the innovator can reduce market competition by not sharing technology, which leads to greater profits. We can conclude from the above analysis that for an innovating enterprise, the decision to share technology depends on whether it can earn more profit. Both enterprises may consider technology sharing only if it is sufficiently profitable to obtain sharing revenues without allowing competitors to influence their competitive position, which is an essential barrier to technology sharing between enterprises in reality.

Result 1-2: The effect of e and $r$ on the equilibrium results of Model L:

(1) For $e \leq \frac{a\left(-r^{2}-3 r+9\right)}{3\left(-4 r^{2}+r+18\right)}, \frac{\partial f^{*}}{\partial e}>0, \frac{\partial \pi_{1}^{R S}}{\partial e}>0, \frac{\partial \pi_{2}^{R S}}{\partial e} \leq 0, \frac{\partial C S^{R S}}{\partial e}>0, \frac{\partial S W^{R S}}{\partial e}>0 ; \frac{\partial f^{*}}{\partial r} \geq 0, \frac{\partial \pi_{1}^{R S}}{\partial r}<$ 
$0, \frac{\partial \pi_{2}^{R S}}{\partial r}<0, \frac{\partial C S^{R S}}{\partial r}>0, \frac{\partial S W^{R S}}{\partial r}<0$.

(2) For $e>\frac{a\left(-r^{2}-3 r+9\right)}{3\left(-4 r^{2}-r+18\right)}, \frac{\partial f^{*}}{\partial e}<0, \frac{\partial \pi_{1}^{R S}}{\partial e}<0, \frac{\partial \pi_{2}^{R S}}{\partial e}>0, \frac{\partial C S^{R S}}{\partial e}>0, \frac{\partial S W^{R S}}{\partial e}>0 ; \frac{\partial f^{*}}{\partial r}<0, \frac{\partial \pi_{1}^{R S}}{\partial r}<$ $0, \frac{\partial \pi_{2}^{R S}}{\partial r}=0, \frac{\partial C S^{R S}}{\partial r}>0, \frac{\partial S W^{R S}}{\partial r}<0$.

We find that consumer surplus and social welfare can be enhanced by innovation returns growth. When e is below the critical value, the increase in returns on innovation is beneficial to improving the sharing fee and the profit of Enterprise 1. When the two enterprises produce completely differentiated products, the profit of Enterprise 2 is not affected by returns on innovation because completely differentiated products help to lower the competition. When e surpasses the critical value, as the returns on innovation grow, there is an increase in the profit of Enterprise 2 and a decline in the sharing fee and the profit of Enterprise 1. It can be seen that even a lower sharing fee can make the innovator's profit higher than that without technology sharing when the innovation returns are promoted to a certain level.

The growth in product differentiation boosts the profits and social welfare of Enterprise 1 but suppresses consumer surplus. At a high level of product differentiation, Enterprise 1 is under lower competitive pressure and is more likely to charge a lower sharing fee. However, when the returns on innovation are above a certain level, technology sharing from Enterprise 1 to Enterprise 2 will result in a significant reduction in Enterprise 2's production costs. Moreover, the profit of Enterprise 2 is not affected by product differentiation. An increase in product differentiation can lead to a rise in the price of Enterprise 2's product, thus boosting Enterprise 2's profit, yet it can also lead to an increase in sharing fees, which harms Enterprise 2's profit. The two effects exactly cancel each other out, making Enterprise 2's profit unchanged.

Enterprise 1 engages in technological innovation in Stage 1 if it shares technology in Stage 2. The condition $\pi_{1}^{R N}-\pi_{1}^{N N} \geq 0$ can be described as

$F \leq \frac{[2 a(3-r)+3 e] e}{2\left(9-2 r^{2}\right)}$

Result 1-3:

Let $F_{0}=\frac{[2 a(3-r)+3 e] e}{2\left(9-2 r^{2}\right)}, \frac{\partial F_{0}}{\partial e}>0$. If $r \leq \frac{3\left(2 a+e-\sqrt{2 a^{2}+4 a e+e^{2}}\right)}{2 a}$, then $\frac{\partial F_{0}}{\partial r} \leq 0$; if $r>$ $\frac{3\left(2 a+e-\sqrt{2 a^{2}+4 a e+e^{2}}\right)}{2 a}$, then $\frac{\partial F_{0}}{\partial r}>0$.

Result 1-3 infers that the fixed costs of innovation, the returns on innovation, and product differentiation can affect Enterprise 1's decision to innovate. If the fixed costs of innovation are too high or the returns of innovation are too low, then the possibility of technological innovation for Enterprise 1 will be reduced. When $F$ and e are constant, higher product differentiation ( $r$ is close to zero) tends to increase fixed marginal costs, and Enterprise 1 is more likely to innovate.

\subsection{Results of Model F}

In Stage 3, we can obtain the equilibrium results. In Stage 2, Enterprise 2 decides whether to share the technology, and Enterprise 1 decides whether to accept the sharing. 
Result 2-1: The optimal sharing fee of Model F is:

(1) If $e \leq \frac{a(3-r)}{-4 r^{2}+r+18}$, then $f^{*}=e$.

(2) If $\frac{a(3-r)}{-4 r^{2}+r+18}<e \leq \min \left[e_{1}(r), e_{2}(r)\right]$, where $e_{1}(r)=\frac{a}{2 r+5}$ and $e_{2}(r)=$ $\frac{a\left(-16 r^{5}+27 r^{4}+141 r^{3}-234 r^{2}-297 r+486\right)+4 a\left(\frac{9}{2}-r^{2}\right) \sqrt{\left.r^{6}-18 r^{5}+75 r^{4}+45 r^{3}-\frac{1611}{4} r^{2}-81 r+729\right)}}{-80 r^{6}+32 r^{5}+957 r^{4}-288 r^{3}-3762 r^{2}+648 r+4860}$, then $f^{*}=$ $\frac{(3-r) a-\left(-4 r^{2}+r+15\right) e}{3}$, where $\frac{\partial e_{2}(r)}{\partial r}<0, \frac{\partial e_{1}(r)}{\partial r}<0$.

(3) If $e>\min \left[e_{1}(r), e_{2}(r)\right]$, then there is no technology sharing.

Result 2-1 implies that when Enterprise 2 (the follower) is the innovator, it is similar to the situation when Enterprise 1 acts as the innovator. Only when $\mathrm{e} \leq \min \left[e_{1}(r), e_{2}(r)\right]$ do the two enterprises share technology. The returns on innovation can affect the choice of sharing strategy between enterprises producing differentiated products. When the returns on innovation are relatively high, a higher level of product differentiation will promote technology sharing.

Result 2-2: The effect of e and on the equilibrium results of Model F:

(1) For $e \leq \frac{a(3-r)}{-4 r^{2}+r+18}, \frac{\partial f^{*}}{\partial e}>0, \frac{\partial \pi_{1}^{R S}}{\partial e} \leq 0, \frac{\partial \pi_{2}^{R S}}{\partial e}>0, \frac{\partial C S^{R S}}{\partial e}>0, \frac{\partial S W^{R S}}{\partial e}>0 ; \frac{\partial f^{*}}{\partial r}=0, \frac{\partial \pi_{1}^{R S}}{\partial r}<0$, $\frac{\partial \pi_{2}^{R S}}{\partial r}<0, \frac{\partial C S^{R S}}{\partial r}>0, \frac{\partial S W^{R S}}{\partial r}<0$.

(2) For $e>\frac{a(3-r)}{-4 r^{2}+r+18}, \frac{\partial f^{*}}{\partial e}<0, \frac{\partial \pi_{1}^{R S}}{\partial e}>0, \frac{\partial \pi_{2}^{R S}}{\partial e}<0, \frac{\partial C S^{R S}}{\partial e}>0, \frac{\partial S W^{R S}}{\partial e}>0 ; \frac{\partial f^{*}}{\partial r} \leq 0, \frac{\partial \pi_{1}^{R S}}{\partial r} \leq 0$, $\frac{\partial \pi_{2}^{R S}}{\partial r}<0, \frac{\partial C S^{R S}}{\partial r}>0, \frac{\partial S W^{R S}}{\partial r}<0$.

The relationships between $e$ and CSRS and between $e$ and $S W^{R S}$ are all positive, indicating that an increase in innovation returns is conducive to improving consumer surplus and social welfare. If e is under the critical value, increasing innovation returns can boost the sharing fee and Enterprise 2's profit but inhibit Enterprise 1's profit. When the two enterprises produce completely differentiated products, the profit of Enterprise 1 is not affected by the innovation returns. If e surpasses the critical value, increasing innovation returns can promote Enterprise 1's profit but suppress the sharing fee and Enterprise 2's profit. The results are similar to those in Result 1-2.

The growth in product differentiation leads to a decrease in consumer surplus but contributes to an increase in social welfare. When $e \leq(a(3-r)) /\left(-4 r^{2}+r+18\right)$, the rise in product differentiation increases the profit of Enterprise 1. However, the optimal sharing fee $f^{*}$ has nothing to do with product differentiation because when the returns on innovation are not significant, Enterprise 2 will not gain an output advantage with its output equal to that without sharing technology, and then Enterprise 2 would choose the highest sharing fee e that Enterprise 1 can accept to obtain higher profits. When $e>(a(3-r)) /\left(-4 r^{2}+r+18\right)$, the sharing fee and the profit of Enterprise 1 can be promoted with the growth in product differentiation. Compared with Result 1-2, the growth in product differentiation increases the profit of the enterprise accepting technology sharing. The growth in product differentiation can increase the price of Enterprise 1's product, which is beneficial to improving Enterprise 1's profit. Yet, it can also lead to an increase in sharing fees, which suppresses the increase in Enterprise 1's profit. However, the growth in product price is higher than that in sharing fees, which has a positive effect on Enterprise 1's profit. Also, we can 
conclude that when the follower is an innovator, it is more advantageous for both the follower and the leader to cooperate with an enterprise whose products are more differentiated.

If the two enterprises share technology in the second stage, then the condition must be satisfied as

$$
F \leq \frac{e(r-3)(r+3)\left[2\left(r^{2}+3 r-9\right) a+\left(r^{2}-9\right) e\right]}{6\left(9-2 r^{2}\right)^{2}}
$$

Result 2-3:

Let $F_{0}=\frac{e(r-3)(r+3)\left[2\left(r^{2}+3 r-9\right) a+\left(r^{2}-9\right) e\right]}{6\left(9-2 r^{2}\right)^{2}}$, we have $\frac{\partial F_{0}}{\partial e}>0$ and $\frac{\partial F_{0}}{\partial r}<0$.

As shown in Result 2-3, the fixed costs of innovation, the returns on innovation, and product differentiation can affect Enterprise 2's decision to innovate. In the case of Enterprise 2 as the innovator, reducing the fixed costs of innovation and promoting differentiated development is still the key to stimulating innovation.

\subsection{Comparative Results}

By comparing the equilibrium outcomes under Model L and Model F, Result 3-1 can be deduced. $\left.\pi^{R S}, C S^{R S}, S W^{R S}, \pi^{R S^{*}}, C S^{R S^{*}}\right)$, and $\left.S W^{R S^{*}}\right)$ are defined as total profits, consumer surplus, and social welfare under different innovators (leader or follower).

Results 3-1: Comparative results are as follows.

(1) When $r \leq 0.3845$, if $\frac{2 a r^{2}}{9-r^{2}} \leq e<e_{3}^{*}(r)$ or $e \geq \frac{(3-2 r) a}{-4 r^{2}+2 r+15}$, then $\pi^{R S} \geq \pi^{R S^{*}}$; if $e<\frac{2 a r^{2}}{9-r^{2}}$ or $e_{3}^{*}(r) \leq e<\frac{(3-2 r) a}{-4 r^{2}+2 r+15}$, then $\pi^{R S} \leq \pi^{R S^{*}} \cdot e_{3}^{*}(r)=$ $-\frac{a\left(r^{4}+69 r^{3}-126 r^{2}-243 r+405\right)-3 a \sqrt{16 r^{8}-96 r^{7}+52 r^{6}+924 r^{5}-1935 r^{4}-1296 r^{3}+5913 r^{2}-3888 r+729}}{-143 r^{4}+144 r^{3}+1044 r^{2}-594 r-1944}$

When $0.3845 \leq r<0.3849$, if $\frac{2 a r^{2}}{9-r^{2}} \leq e<e_{3}^{*}(r)$ or $e \geq \frac{a(3-r)}{-4 r^{2}+r+18}$, then $\pi^{R S} \geq \pi^{R S^{*}}$; if $e<$ $\frac{2 a r^{2}}{9-r^{2}}$ or $e_{3}^{*}(r) \leq e<\frac{a(3-r)}{-4 r^{2}+r+18}$, then $\pi^{R S} \leq \pi^{R S^{*}}$.

When $0.3849 \leq r<0.7304$, if $e \geq \frac{2 a r^{2}}{9-r^{2}}$, then $\pi^{R S} \geq \pi^{R S^{*}}$; if $e<\frac{2 a r^{2}}{9-r^{2}}$, then $\pi^{R S} \leq \pi^{R S^{*}}$.

When $r \geq 0.7304$, if $e \geq e_{4}^{*}(r)$, then $\pi^{R S} \geq \pi^{R S^{*}}$; if $e<e_{4}^{*}(r)$, then $\pi^{R S} \leq \pi^{R S^{*}} . e_{4}^{*}(r)=$ $-\frac{a\left(r^{4}+69 r^{3}-126 r^{2}-243 r+405\right)+3 a \sqrt{16 r^{8}-96 r^{7}+52 r^{6}+924 r^{5}-1935 r^{4}-1296 r^{3}+5913 r^{2}-3888 r+729}}{-143 r^{4}+144 r^{3}+1044 r^{2}-594 r-1944}$

(2) When $r<0.3845$, if $e<\frac{(3-2 r) a}{-4 r^{2}+2 r+15}$, then $C S^{R S} \geq C S^{R S^{*}}$; if $e \geq \frac{(3-2 r) a}{-4 r^{2}+2 r+15}$, then $C S^{R S} \leq$ $C S^{R S^{*}}$. When $r \geq 0.3845$, if $e<e_{5}^{*}(r)=$ $-a\left(29 r^{4}-111 r^{3}-90 r^{2}+405 r\right)+3 a \sqrt{256 r^{8}-744 r^{7}-3276 r^{6}+9828 r^{5}+13203 r^{4}-38610 r^{3}-22599 r^{2}+43254 r+26244}$ $209 r^{4}-216 r^{3}-1548 r^{2}+918 r+2916$ , then $C S^{R S} \geq C S^{R S^{*}}$; if $e \geq e_{5}^{*}(r)$, then $C S^{R S} \leq C S^{R S^{*}}$.

(3) When $r<0.3845$, if $e<\frac{(3-2 r) a}{-4 r^{2}+2 r+15}$, then $S W^{R S}>S W^{R S^{*}}$; if $e \geq \frac{(3-2 r) a}{-4 r^{2}+2 r+15}$, then $S W^{R S} \leq S W^{R S^{*}}$. When $r \geq 0.3845$, if $e<e_{6}^{*}(r)=$ $\frac{-a\left(32 r^{4}+96 r^{3}-468 r^{2}-324 r+1215\right)+3 a \sqrt{\left(-8 r^{6}-96 r^{5}+36 r^{4}+1584 r^{3}-1350 r^{2}-5400 r+6561\right)\left(9-2 r^{2}\right)}}{2\left(-110 r^{4}+108 r^{3}+792 r^{2}-432 r-1458\right)}$, then $S W^{R S} \geq S W^{R S^{*}}$; if $e \geq e_{6}^{*}(r)$, then $S W^{R S} \leq S W^{R S^{*}}$. 


\section{DISCUSSION}

The results of this paper reveal the conditions for technology sharing and the factors that influence technology innovation and sharing behavior. First, enterprises' strategies for innovation and technology sharing are affected by fixed costs of innovation, returns on innovation, and product differentiation. It is less likely for enterprises to innovate if the fixed costs of innovation are too high, the returns on innovation are too low, or the products are too homogeneous. Moreover, the returns on innovation influence the decision to share between the two enterprises under different product differentiation conditions. If the returns on innovation are low, two enterprises with different product differentiation can cooperate easily. If the returns on innovation are high, technology sharing can only be achieved between two enterprises with relatively high product differentiation. Hence, we should create a favorable environment for enterprises to innovate and adopt various incentive measures, such as subsidies and tax preferences, to reduce the fixed costs of enterprises' innovation and promote differentiated development, which is the focus of many countries' policies to encourage innovation. Notably, for high-yield innovations, technology sharing among homogeneous enterprises is often unrealistic, and more attention should be paid to technology transferability to reduce barriers to technical cooperation between enterprises.

Second, the optimal sharing fee is affected by the subject of innovation, innovation returns, and product differentiation. The combinations of different returns on innovation and product differentiation have an impact on sharing fees by affecting the cost structure and the product price. If the returns on innovation change under a particular value, the growth in the returns on innovation will increase the sharing fee. If the returns on innovation change above a certain value, the growth in the returns on innovation will lower the sharing fee. Product differentiation has different impacts on sharing fees under different innovators. Under a rather low level of returns on innovation, product differentiation is negatively correlated with the sharing fee in Model L, whereas product differentiation has nothing to do with the sharing fee in Model F. The similarity lies in that when there are relatively high returns on innovation, higher product differentiation is conducive to increasing the sharing fee. These results imply that the government should comprehensively consider various factors, such as innovation entities, innovation benefits, and product differentiation, in designing a policy mix that reduces technology-sharing fees.

Third, by comparing the technology sharing effects under the two models, we find that: For the profit of the leader and the follower respectively, when the leader is an innovator, if the returns on innovation are relatively large, the degree of product differentiation does not affect the profit for the follower, making cooperation between the two enterprises more likely to occur; when the follower is the innovator, it is more advantageous for both the follower and the leader to cooperate if the products are more differentiated. For the total profits under the two models, if the returns on innovation are extremely large, the leader may be a better innovator; if the returns on innovation are relatively small, the follower may be a better innovator. However, if the returns on innovation are at a fairly medium level, the results are complicated. For the impacts of the returns on innovation and product differentiation on consumer surplus and social welfare, the returns on innovation are positively related to consumer surplus and social welfare. In contrast, higher product differentiation can produce lower consumer surplus and higher social welfare. For consumer surplus and social welfare under the two models, if the returns on innovation 
are relatively small, the leader acting as the innovator may bring higher consumer surplus and social welfare; if the products are homogeneous, the follower is likely to be a better innovator. Therefore, when technology sharing exists, enterprises should pay attention to the reasonable combination of returns on innovation and product differentiation to bring greater profits. When the government chooses the optimal sharing strategy and the optimal innovator, the different returns on innovation and product differentiation should be considered cautiously.

The results of this article show that product differentiation and cost have important impacts on technology licensing and innovation behavior, which is consistent with existing research (e.g., Yan \& Yang, 2018; Badia, 2019; Hsu, 2019). This paper considers the case in which the follower is the innovative enterprise, which contributes to the existing literature. From our results, consumer surplus and social welfare are affected in various ways when the subjects of innovation are different. This finding is different from Cao \& Kabiraj (2018). They report that when a royalty contract is available, the total profits, consumer surplus, and social welfare with the leader innovating are identical to those with the follower innovating. In our paper, both Enterprise 1 (the leader) and Enterprise 2 (the follower) may be the optimal bearers of social responsibility depending on the returns on innovation and product differentiation. However, this article assumes that the innovative enterprise adopts per-unit royalty and analyses the optimal fee, and does not consider other technology sharing models and other oligopoly markets. Generally, the results in this article have positive reference value for enterprises making decisions about innovation, sharing technology, and government policies in a Stackelberg market. And the results have some guidance for private-owned enterprises and public-protected services. For private-owned enterprises, the results can help private-owned enterprises to gain development opportunities, reach international technology cooperation through technology sharing, enjoy the benefits of global technology flow, and create a better market environment for their development. For public-protected services, the results can help the government to adopt royalty subsidies and tax incentives to provide government support for access to advanced technology for publicly protected services, thereby ensuring the position of publicly covered services in the marketplace and helping them to improve their international competitiveness.

\section{CONCLUSION}

This paper establishes a Stackelberg model consisting of a leader and a follower to investigate the leader's and follower's decisions about innovation and technology sharing and explore the optimal sharing fees under different conditions. We find that fixed costs of innovation, innovation returns, and product differentiation affect the optimal sharing fee and enterprises' strategies for innovation and technology sharing. The effects of technology sharing on enterprises, consumers, and social welfare are affected by innovation, which is also influenced by returns on innovation and product differentiation. Our findings provide valuable references for enterprises to optimize their innovation and technology sharing strategies and enhance competitiveness in a Stackelberg competition market. In addition, enterprises' decisions to innovate and share technology are made to improve competitiveness and thus obtaining the maximum profit, which can contribute to the improvement of social welfare in some circumstances. To promote the optimal allocation of industry resources and improve social welfare, the government should fully understand the 
enterprise cost, innovation returns, product differentiation, and other information and specify the optimal guiding policies for innovation and technology sharing.

This paper has some limitations that need to be improved upon in the future. First, the article only considers royalty, which can be expanded to a two-part tariff in the future. Second, the paper does not endogenize the oligopoly type and consider different property rights; constructing an endogenous timing game in a mixed duopoly can be a future research direction. Third, the paper assumes that only two competitors and the analysis can be expanded to more subjects in the future.

\section{Acknowledgment}

This work was supported by the Fundamental Research Funds for the Central Universities (Grant number: N2123006), the Education Department Project of Jilin Province (Grant number: JJKH20211238 SK), Major Project of Philosophy and Social Sciences Key Research Base of Jilin University (Grant number: 2020XXJD13), Undergraduate Teaching Reform Research Project of Jilin University (Grant number: 2021XZC022), and the MOE Project of Key Research Institute of Humanities and Social Sciences.

\section{References}

1. Amemiya Y., Ishihara A., \& Nakamura T. (2020). Pre-emptive Production and Market Competitiveness in Oligopoly with Private Information. Journal of Economics \& Management Strategy, 1-7. https://dx.doi.org/10.1111/jems.12410

2. Aravossis, K. G., Kapsalis, V. C., Kyriakopoulos, G. L., \& Xouleis, T. G. (2019). Development of a Holistic Assessment Framework for Industrial Organizations. Sustainability, 11 (14), 3946. http://dx.doi.org/10.3390/su11143946

3. Badia, B. D. (2019). Patent Licensing and Technological Catch-up in a Heterogeneous Duopoly. Review of Industrial Organization, 55, 287-300. http://dx.doi.org/10.1007/s11151-018-09675-1

4. Cao, J., \& Kabiraj, T. (2018). Technology Transfer in a Stackelberg Structure: Licensing Contracts and Welfare. The Manchester School, 86 (5), 695-697. http://dx.doi.org/10.1111/ manc. 12227

5. Cao, J., \& Sinha, U. B. (2020). Intra-brand Patent Licensing with Inter-brand Competition. Mathematical Social Sciences, 104, 71-77. http://dx.doi.org/10.1016/j.mathsocsci.2020.01.001

6. Chen, J., Liu, J., \& Qin, Q. (2019). Corporate Social Responsibility and Capacity Selection. Transformations in Business \& Economics, 1 (3C), 530-545.

7. Chen, J., Wang, X., \& Chu, Z. (2020a). Capacity Sharing, Product Differentiation and Welfare. Ekonomska Istrazivanja-Economic Research, 33 (1), 107-123. http://dx.doi.org/10.1080/133167 7X.2019.1710234

8. Chen, J., Xie, X., Liu, J., \& Liu, R. (2020b). Externality, Product Differentiation and Social Welfare in Education Market. Transformations in Business \& Economics, 19 (3C), 522-541.

9. Cheng, J., Gong, B., \& Li, B. (2018). Cooperation Strategy of Technology Licensing Based on Evolutionary Game. Annals of Operations Research, 268, 387-404. http://dx.doi.org/10.1007/ s10479-017-2461-z 
10. Colombo, S., \& Filippini, L. (2015). Patent Licensing with Bertrand Competitors. The Manchester School, 83 (1), 1-16. http://dx.doi.org/10.1111/manc.12050

11. Din, H. R., \& Sun, C. H. (2020). Welfare Improving Licensing with Endogenous Choice of Prices Versus Quantities. North American Journal of Economics and Finance, 51, 100859. http:// dx.doi.org/10.1016/j.najef.2018.10.007

12. Fan, C., Jun, B. H., \& Wolfstetter, E. G. (2018). Optimal Licensing under Incomplete Information: The Case of the Inside Patent Holder. Economic Theory, 66 (4), 979-1005. http:// dx.doi.org/ 10.1007/s00199-017-1077-5

13. Ferreira, F. A., \& Bode, O. R. (2020). Licensing Under Cournot vs. Bertrand Competition. Economic Research-Ekonomska Istrazivanja, 34 (1), 1651-1675. http://dx.doi.org/10.1080/133167 7X.2020.1844586

14. Ferreira, F., \& Bode, O. R. (2013). Licensing Endogenous Cost-reduction in a Differentiated Stackelberg Model. Communications in Nonlinear Science and Numerical Simulation, 18 (2), 308-315. http://dx.doi.org/10.1016/j.cnsns.2012.07.001

15. Gelves, J. A., \& Heywood, J. S. (2016). How does a Mixed Ownership Firm License a Patent? Economic Modelling, 59, 278-284. http://dx.doi.org/10.1016/j.econmod.2016.07.018

16. Hong, X., Yang, L., Zhang, H., \& Zhao, D. (2014). The Optimal Licensing Contract in a Differentiated Stackelberg Model. The Scientific World Journal, 4379191. http://dx.doi. org/10.1155/2014/437919

17. Hsu, J., Liu, L., Wang, X. H., \& Zeng, C. (2019). Ad Valorem Versus Per-unit Royalty Licensing in a Cournot Duopoly Model. The Manchester School, 87 (6), 890-901. http://dx.doi. org/ 10.1111/manc.12280

18. Jeon, D. S., \& Lefouili, Y. (2018). Cross-licensing and Competition. Rand Journal of Economics, 49 (3), 656-671. http://dx.doi.org/10.1111/1756-2171.12248

19. Kabiraj, A., \& Kabiraj, T. (2017). Tariff Induced Licensing Contracts, Consumers' Surplus and Welfare. Economic Modelling, 60, 439-447. http://dx.doi.org/10.1016/j.econmod.2016.11.001

20. Kapsalis, V. C., Kyriakopoulos, G. L., \& Aravossis, K. G. (2019). Investigation of Ecosystem Services and Circular Economy Interactions under an Inter-organizational Framework. Energies, 12 (9), 1734. http://dx.doi.org/10.3390/en12091734

21. Kishimoto, S. (2020). The Welfare Effect of Bargaining Power in the Licensing of a CostReducing Technology. Journal of Economics, 129 (2), 173-193. http://dx.doi.org/ 10.1007/s00712019-00672-w

22. Kitagawa, T., Masuda, Y., \& Umezawa, M. (2020). Impact of Technology Development Costs on Licensing Form in a Differentiated Cournot Duopoly. International Journal of Economic Theory, 16, 153-166. http://dx.doi.org/10.1111/ijet.12175

23. Kyriakopoulos, G. L., Kapsalis, V. C., Aravossis, K. G., Zamparas, M., \& Mitsikas, A. (2019). Evaluating Circular Economy under a Multi-Parametric Approach: A Technological Review. Sustainability, 11 (21), 6139. http://dx.doi.org/10.3390/su11216139

24. Li, C., \& Ji, X. (2010). Innovation, Licensing, and Price vs. Quantity Competition. Economic Modelling, 27 (3), 746-754. http://dx.doi.org/10.1016/j.econmod.2010.01.017 
25. Li, Y., \& Yanagawa, T. (2011). Patent Licensing of Stackelberg Manufacturer in a Differentiated Product Market. International Journal of Economic Theory, 7, 7-20. http://dx.doi. $\operatorname{org} / 10.1111 / j .1742-7363.2010 .00146 . x$

26. Moreira, S., Cabaleiro, G., \& Reichstein, T. (2019). Licensing Decision: A Rent Dissipation Lens Applied to Product Market Competition, Openness to External Knowledge and Exogenous Sunk Costs. Industrial and Corporate Change, 28 (4), 37-48. http://dx.doi. org/10.1093/icc/dty0361

27. Nguyen, X., Sgro, P., \& Nabin, M. (2017). Optimal Licensing Policy under Vertical Product Differentiation. Review of Development Economics, 21 (3), 497-510. http://dx.doi.org/10.1111/ rode. 12270

28. Niu, S. (2019). Licensing Versus Assignment: Innovation Transfer in an Asymmetric Duopoly. Journal of Public Economic Theory, 21 (6), 1286-1308. http://dx.doi.org/10.1111/jpet.12414

29. Poddar, S., \& Sinha, U. B. (2010). Patent Licensing from a High-cost Firm to a Low-cost Firm. The Economic Record, 86 (274), 384-395. http://dx.doi.org/10.1111/j.1475-4932.2010.00633.x

30. San Martin, M., \& Saracho, A. I. (2015). Two-part Tariff Licensing Mechanisms. The Manchester School, 83 (3), 288-306. http://dx.doi.org/10.1111/manc.12059

31. San Martin, M., \& Saracho, A. I. (2016). Patent Strength and Optimal Two-part Tariff Licensing with a Potential Rival Incorporating Ad Valorem Royalties. Economics Letters, 143, 28-31. http://dx.doi.org/10.1016/j.econlet.2016.03.006

32. Sen, D., \& Tauman, Y. (2018). Patent Licensing in a Cournot Oligopoly: General Results. Mathematical Social Sciences, 96, 773-792. http://dx.doi.org/10.1016/j.mathsocsci.2018.08.001

33. Tsai, C. S., Tsai, T. C., Ko, P. S., Lee, C. H., Lee, J. Y., \& Wang, Y. L. (2019). On the Sustainability of Technology Licensing under Asymmetric Information Game. Sustainability, 11, 6959. http://dx.doi.org/10.3390/su11246959

34. Wang, J., Wu, X., \& Krishnan, V. (2018). Decision Structure and Performance of Networked Technology Supply Chains. Manufacturing and Service Operations Management, 20 (2), 199-216. http://dx.doi.org/10.1287/msom.2017.0619

35. Wang, K. C. A., Liang, W. J., \& Chou, P. S. (2013). Patent Licensing under Cost Asymmetry Among Firms. Economic Modelling, 31 (1), 297-307. http://dx.doi.org/10.1016/j. econmod.2012.11.025

36. Wang, L. F. S., Mukherjee, A., \& Zeng, C. (2020). Does Technology Licensing Matter for Privatization? Journal of Public Economic Theory, 22 (5), 1462-1480. https://dx.doi.org/10.1111/jpet.12431

37. Xu, H., \& Tan, D. (2019). Optimal Abatement Technology Licensing in a Dynamic Transboundary Pollution Game: Fixed Fee Versus Royalty. Computational Economics, 1-13. http://dx.doi.org/10.1007/s10614-019-09909-8

38. Yan, Q., \& Yang, L. (2018). Optimal Licensing in a Differentiated Bertrand Market under Uncertain R\&D Outcomes and Technology Spillover. Economic Modelling, 68, 117-126. http:// dx.doi.org/10.1016/j.econmod.2017.06.013

39. Yang, F., Jiao, C. \& Ang, S. (2019). The Optimal Technology Licensing Strategy under Supply Disruption. International Journal of Production Research, 57 (7), 2057-2082. http://dx.doi.org/10.10 80/00207543.2018.1521535 
40. Zhang, H., Wang, X., Hong, X., \& Lu, Q. (2018). Technology Licensing in a Network Product Market: Fixed-Fee versus Royalty Licensing. Economic Record, 94, 168-185. http://dx.doi. org/10.1111/1475-4932.12385

41. Zhang, H., Wang, X., Qing, P., \& Hong, X. (2016). Optimal Licensing of Uncertain Patents in a Differentiated Stackelberg Duopolistic Competition Market. International Review of Economics \& Finance, 45, 215-229. http://dx.doi.org/10.1016/j.iref.2016.06.003

42. Zou, Y., \& Chen, T. L. (2020). Quality Differentiation and Product Innovation Licensing. Economic Modelling, 87, 372-382. http://dx.doi.org/10.1016/j.econmod.2019.08.010

\section{Contact information}

prof. Junlong Chen, Ph.D.

Northeastern University

School of Humanities and Law

China

E-mail:shikuangzhiwang@126.com

ORCID: 0000-0001-8962-2567

Ziban Wei, Undergraduate

Northeastern University at Qinhuangdao

School of Economics

China

E-mail:weizihan0209@126.com

ORCID: 0000-0001-9302-8253

assoc. prof. Jiali Liu, Ph.D. (Corresponding author)

Jilin University

Center for China Public Sector Economy Research/School of Economics

China

E-mail:liujiali@jlu.edu.cn

ORCID: 0000-0002-1168-3295

dr. Xiaosong Zheng

University of Technology Sydney

UTS Business School

Australia

E-mail:xiaosong.zheng@uts.edu.au

ORCID: 0000-0002-6388-3619 